\title{
Chapter 4 \\ Three-Dimensional Reconstruction Model and Numerical Simulation of Rock \\ Fissures
}

\subsection{Introduction}

The problem of rockmass sudden destruction is closely related to the existence and evolution of fissures. The development and evolution of rock fissures under loading pass three stages: the stage of secondary crack initiation, the stage of formation of macro-fracture zone and the stage of localized deformation. In this chapter, three-dimensional reconstruction model of rock fracture was carried out in order to further reveal the damage mechanism of rockmass and the evolution pattern of fracture cracks. In order to further reveal the damage mechanism of rockmass instability, predicting rockburst during the process of damage evolution and rockmass instability was organically combinated.

With the development and improvement of computer technology, the digital image processing technology has gradually developed into an emerging discipline. It mainly converts the changing process of object into a digital image stored in an electronic computer, and application of computer to deal with image information obtained and analysis to get the required results. Although many scholars applied digital image processing technology to quantitatively describe and effectively reveal the evolution and damage of cracks. A lot of work was analyzed using CT image and three-dimensional reconstruction model of fissures (Kawakata et al. 1999, 2000). Moreover, using the X-ray, CT scanning experiment was used to simulate the joint distribution and trend of rockmass (Ueta et al. 2000). Three-dimensional reconstruction model and numerical simulation of CT images were established on the basis of digital image. It is necessary to use numerical simulation for more accurate characterization and description of rock and reflecting the actual force of rockmass. Therefore, based on the digital image processing technique, there is a new approach to study the mechanical properties of rocks by analyzing the CT scan image and the three-dimensional reconstruction model.

Kawakata et al. (1999) conducted three-dimensional reconstruction model of two-dimensional cracks images using the CT scan data of rock samples, and made 
analysis of shape and spatial distribution of cracks. Ueta et al. (2000) carried out three-dimensional reconstruction model of indoor sandstone during shear; the shear zone of inner space was reproduced, and analyzed the intersected structure of outer sedimentary layer. Ruiz de Argandona et al. (1999) studied the pore structure of rocks using CT scanning technology, and reconstructed the three-dimensional pore structure of rock, the inhomogeneity of pore distribution in rock was revealed. Using CT image information, the extension evolution of rock weakening and pore was dynamically tracked and described. Wang et al. (2003) studied the damage of mechanical properties of concrete materials using of CT scanning technology, the concrete two-dimensional full-scan images were obtained, three-dimensional reconstruction model was verified the relationship between damage parameters and mechanical modeling. Viggiani et al. (2004) assessed the evolution and development of shear bands by analyzing the spatial resolution X-rays under a fine-grained hard soil partial load.

Bornert et al. (2010) studied the strain localization characteristics of clay rocks under triaxial compression using the X-ray micro CT. Feng et al. (2004) investigated the mechanism of sandstone damage evolution by real-time $\mathrm{CT}$, and proposed a damage model based on chemical corrosion and CT value. Louis et al. (2006) solved the positioning features of 3D geometric shapes and develop them into the braces using the high resolution X-ray CT imaging technique, and obtained the associated with the maximum compressive stress. Nasseri et al. (2011) obtained the reasonable fracture toughness anisotropy of Bale granite, and reflects the difference of damage structure using a three-dimensional object counter plug-in technique method. Chen et al. (2007) proposed a three-dimensional numerical simulation methods based on digital images of rock failure.

Three-dimensional reconstruction model technique can be used to observe the changes of geotechnical structure under multi-dimension and without disturbance, and observe the microstructural changes of samples, the movement of meso-particles, the development of fissures, and the local density. The three-dimensional reconstruction model technique realizes the visualization of cracks distribution at different stages of loaded rock samples. It can not only visually observe the evolution of rock failure, but also describe the spatial distribution of medium of rock material accurately. Based on the image data of rock using CT scan, this chapter used the digital image processing technology to extract the useful information from the CT images and reconstruct the three-dimensional model based on MATLAB software. 


\subsection{CT Scanning Experiment Under Uniaxial Cyclic Load/Unload}

In load/unload test, the rock samples generated many microcracks under the external load, the microcrack initializes, expands and penetrates, eventually leading to macroscopic destruction. In order to further reveal the predicting of rockburst, it is necessary to study the evolution pattern of internal microstructure of rock samples. CT scanning can be used to obtain the internal structural changes of rock samples. CT images, obtained by CT scanning, can analyze the initiation, expansion, penetrating and final evolution process of microcrack of rock samples.

CT scanning techniques can eliminate interference from other parts of object in the target area, and make objects appear in two-dimensional images in isolation, which can help improve the quality of image. The material composition of object and the damage location are also more clearly and accurately. CT scanning technology is described as follows: Detection receivers and X-ray sources are fixed on the same rack. Then the rack rotates a fixed angle, which indicates the end of a scan, and the detected objection will be in synchronous rotation with the rack. The rack will rotate the same angle at the end of each scan to complete the next scan. The multi-group scanning data can be collected by repeated rotating scanning process. Complete a scan, the rack will rotate once, and 256 data will be collected, if the rack rotates $180^{\circ}, 46,080$ data will be collected. CT images of each scanning level of detected object can be gotten by processing these collecting dates.

In this experiment, based on the result of sandstone samples failure under unaxial loading, the unaxial compressive strength (UCS) of roof sandstone sample is $93.48 \mathrm{MPa}$. Therefore, its UCS under cyclic load/unload can be estimated as $90 \mathrm{MPa}$; the UCS of floor sandstone sample is $58.18 \mathrm{MPa}$. Therefore, its UCS under cyclic load/unload can be estimated as $60 \mathrm{MPa}$; as shown in Fig. 2.7, CT scanning test of sandstone is divided into two phases under unaxial cyclic load/ unload. Upper and lower stress of axial loading at the first stage of cyclic load/ unload is respectively 10 and $30 \%$ of UCS; Upper and lower stress of axial loading at the second stage of cyclic load/unload is respectively 30 and $70 \%$ of UCS, the sample will then be loaded and destroyed. Axial stress is used to control loading. The loading method is cyclic load/unload by constant amplitude; the loading rate of roof sandstone is $500 \mathrm{~N} / \mathrm{s}$, floor sandstone is $300 \mathrm{~N} / \mathrm{s}$. The triangle waveform is selected for loading, in order to ensure that the time of load/unload process is equal, load/unload speed should be consistent (Fig. 4.1).

The specific scanning process of this experiment is as follows:

(1) An initial scan of roof and floor sandstone sample load/unload was carried out to obtain the mesoscopic structure image of rock sample before the cyclic load/unload. 


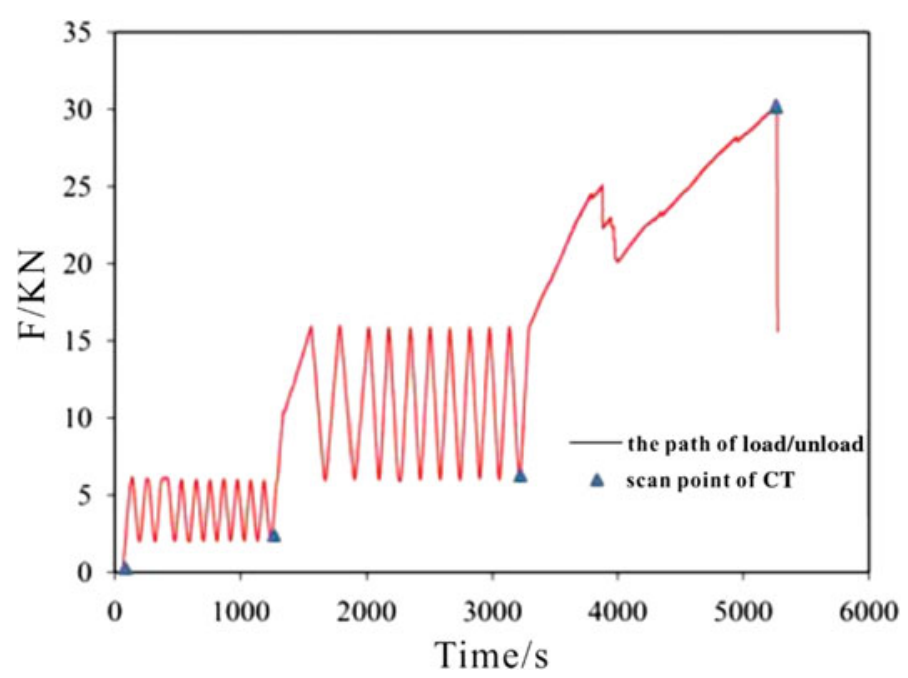

Fig. 4.1 Scan location and path of load/unload of rock sample

Table 4.1 The parameters of

\begin{tabular}{l|l|l|l}
\hline The sample size & $\begin{array}{l}\text { Number of } \\
\text { pieces }\end{array}$ & $\begin{array}{l}\mathrm{U} \\
(\mathrm{kV})\end{array}$ & $\begin{array}{l}\mathrm{I} \\
(\mu \mathrm{A})\end{array}$ \\
\hline$\Phi 50 \times 100$ & 1000 & 145 & 300 \\
\cline { 3 - 4 } & & 110 & 200 \\
\hline
\end{tabular}

(2) Stop loading after 10 cycles at the first stage under cyclic load/unload, completing the second scan of rock sample. The internal microstructure images of roof and floor sandstone load/unload were obtained;

(3) Stop loading after 10 cycles at the second stage under cyclic load/unload, the third scan of rock sample was completed. The internal microstructure images of roof and floor sandstone load/unload were obtained;

(4) Complete the fourth scan of rock sample at the stage of rock failure; the internal microstructure images of roof and floor sandstone after the stage of rock failure were obtained. The parameters of CT scanning were set as Table 4.1.

\subsection{Cracks Extraction and Calculation}

\subsubsection{Processing the CT Images}

\subsubsection{Characteristics of CT Images Information}

CT image of rock samples are qualitative and quantitative information extraction. It is important to consider the possibility of the repeated scanning in the test design. 
The selection of scanning phase should be able to fully reflect the evolution of rock failure, the change of images are be described qualitatively or quantitatively, the occurrence of abnormal conditions are be observed. Repeated scanning experiments are carried out to ensure the accuracy of test results, and it is necessary to detailedly be described the regularity characteristics of rock failure, the error was eliminated in the process of preparing samples, the experimental results were be compared under different loading methods. In order to accurately and effectively analyze the internal structure changes of material presented in the images, it is necessary to fully know about the lithological characteristics of samples, the change of these loaded rock samples is be mastered because of the internal particle friction or the composition of internal matter, the results are due to the change of proportion of a substance or the change of substance density. Avoiding the influence of various objective factors on the images, the change of images can be represented by the abnormal area. In conclusion, it is very important to deeply understand the process of rock failure using the CT scan data.

\subsubsection{CT Image Processing Contents and Methods}

1. CT image processing contents

(1) Arithmetic of image

1) Plus. For the image that continues to be transformed in one direction, the algorithm can refine this change using the weighted average of image successive layers, which can improve the spatial resolution of image to some extent.

2) Subtract. It is a very effective method to detect the internal material migration of samples. Because the change of image data is much smaller than the data itself, this operation can greatly reduce the original artifact of CT images.

3) Multiply. Multiplying the image by a constant, a distribution function, or another image, it can be enhanced to correct or alter the original image to achieve a particular target.

4) Divide. It has the same effect as multiplication.

5) Combinatorial operations. The image is performed on a cumulative basis according to the expected target.

(2) Image enhancement

The meaning of enhanced processing is obtained using some specific information on the change of CT number or expression method of image, while it may change the quantitative significance of CT number. Common methods are as follow:

1) High pass filtering (differential). In the area, gradient technology can be used to focus the image on the image. Using exponential or other 
convolution filtering can improve the image characteristics of center or outer edge. After taking the Fourier transform in the frequency domain, the high-pass filtering is carried out, then these images of inverse Fourier transform is shown, and the spatial change of image is highlighted. Limited high-pass filtering can make the boundary clear, and the recognition of images can be helpful.

2) Low pass filtering (on average). The spatial and frequency domain is used to reduce the parasitic effects of detector space sampling and incomplete algorithm. Although some spatial resolution is overflowed, the image data are more reliable and the image is more gentle and coherent.

3) Histogram equalization. The entire image brightness everywhere maybe cause that the image can't be found at the same time, equalization processing can improve dark space value, reduce light area, it is easier to see these details of image; if the distribution of image values is measured, then these images histogram equalization is used to adjust the data, and the obtained images have better results.

4) Direction filtering. In order to highlight some features of orientations, they can be highlighted, and the less obvious structures are identified.

(3) Image segmentation

Image segmentation is to extract the need to study in the image of local area and according to the regional characteristics of entire process of image classification, through the region of interest in the segmented regions extracted, in order to achieve the goal of observation and analysis. According to the image processing technology, the following two principles are used to divide the research images:

1) The gray value of each pixel is not necessarily continuous in the image, so it can be divided.

2) Due to the similarity of gray values in the same region, the grayscale differences in different regions can be found to be divided.

The above two segmentation methods have certain limitations for different images. Achieving the satisfactory segmentation results, we need have a thorough understanding of image information. Reasonable segmentation methods are selected by its characteristics. Image segmentation can be used to extract the images of rock and damage zones (including holes, microcracks and microdamage that human eyes can hardly observe), and these characteristics that image segmentation is based on may be pixel gray, gray variance of small area, the gray scale distribution, grayscale texture, image point or the color of small area and so on.

(4) Measurement of image data

After mastering the method of image processing on software, a series of images changes of data information can be collected and calibrated in a 
specific way. These continuous collections of data in the same area can be used to analyze the changes in this region. Duo to the data fluctuation range of limited area is small; it is difficult to calibrate the region. In the large area, the area larger than $10 \mathrm{~mm}^{2}$ is normally selected. In order to avoid the influence of data error caused by image distortion, the study area must be tracked.

(5) Distribution of image data

Measuring the gray value of cracks in certain region at different loading stages, the internal structure of rock samples can be studied from the perspective of mesoscopic, which can help to understand the rock damage mechanism more deeply.

2. CT image processing

(1) Image preprocessing. In the process of collecting data of CT images, the influence of surrounding environment and scanning equipment running parts produced by quantization noise affect data collection, the image quality was reduced, the image blur were made, the essential features of images were changed and eliminated, and it was not conducive to the recognition of CT image and analysis. Therefore, it is very important to carry out the initial treatment of CT images without destroying the image information and characteristics. There are many methods for the preprocessing of CT scan images, including brightness adjustment and contrast adjustment. The CT images were imported into MATLAB software; Firstly, the grayscale images could change by grayscale transformation, the scale function provided by the MATLAB toolbox, which would enhance the image contrast. Secondly, the combination of high and low data transformation made the foreground and background gray of image further stretched, highlighting relevant targets and details to enhance the image's function. In the end, the image data was reversed and the image was further enhanced.

(2) Image segmentation. Images were segmented for realizing effectively in the research area, mesoscopic cracks of rock scanned images existed, reducing the influence on image information of all kinds of objective conditions caused by accidental error in the process of CT scanning. Firstly, using the threshold transform to convert grayscale image to binary image, which referred to the image with only black (threshold value 0) and white (threshold value 255) in the image. Secondly, using the morphological operations of image expansion and open the binary region respectively for binary image "extended", "bold" and delete in the binary image area, this was less than a certain value of object. Getting the clear cracks, the image of each processing stage is shown in Fig. 4.2. 


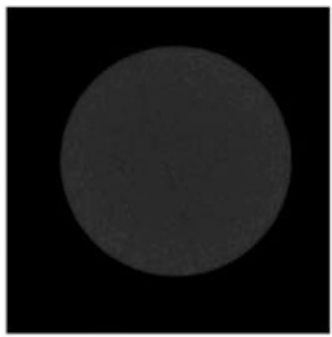

(a)The original image

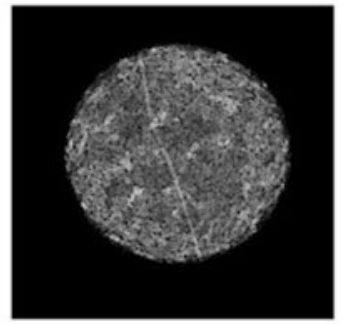

(d)Bottom-Hat transform

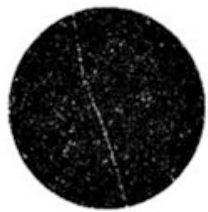

(g)Binarization

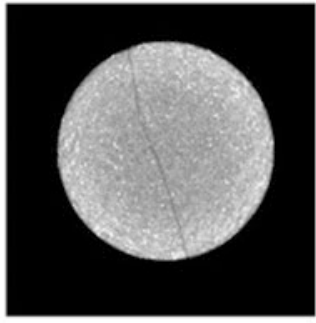

(b)Linear transformation

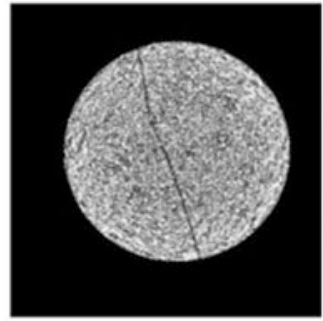

(e) Image subtract

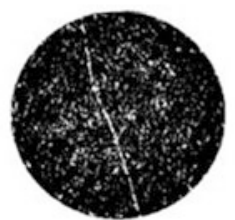

(h)Image expansion

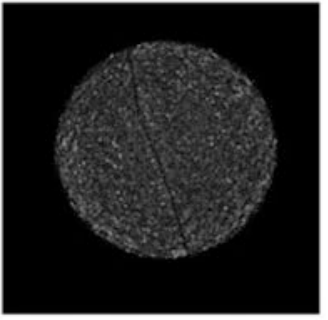

(c)Top-hat transform

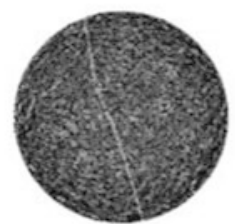

(f)Negate operation

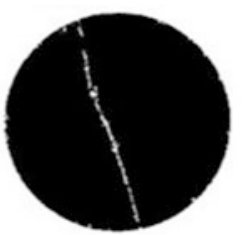

(i) Remove small area objects

Fig. 4.2 Cracks images at each processing stage

\subsubsection{Calculating the Length and Area of Cracks}

\subsubsection{Calculating the Length of Cracks}

The length of cracks were straightened, the number of pixels, occupied by the cracks in the image area, could be obtained by statistical calculation, and then the lengths of cracks could be calculated. In this chapter, the bwperim function in MATLAB software was used to calculate the located cracks length in the region. The edge pixels of cracks could be extracted in the binarized images. The edge pixels of cracks must meet the following conditions: Value is 1 (the white area is the crack area whose pixel value is " 1 "), and at least one value in the adjacent area is 0 , and the bwperim function can display the edge contour of cracks in the images.

The calculation results of cracks lengths at each layer of roof sandstone at different stress conditions are shown in Tables 4.2, 4.3 and Figs. 4.3, 4.4. We can 
Table 4.2 Cracks lengths at each layer of roof sandstone at different stress conditions

\begin{tabular}{l|l|l|l|l}
\hline $\begin{array}{l}\text { Roof } \\
\text { sandstone }\end{array}$ & $\begin{array}{l}\text { Before } \\
\text { loading } \\
(0 \mathrm{MPa})\end{array}$ & $\begin{array}{l}\text { After the first } \\
\text { phase }(9 \mathrm{MPa})\end{array}$ & $\begin{array}{l}\text { After the second } \\
\text { phase }(27 \mathrm{MPa})\end{array}$ & $\begin{array}{l}\text { After failure } \\
(89.1 \mathrm{MPa})\end{array}$ \\
\hline 350 layer & $4.2956 \times 10^{3}$ & $4.5681 \times 10^{3}$ & $4.5968 \times 10^{3}$ & $6.3309 \times 10^{3}$ \\
\hline 450 layer & $4.3096 \times 10^{3}$ & $4.6249 \times 10^{3}$ & $4.8052 \times 10^{3}$ & $6.0482 \times 10^{3}$ \\
\hline 550 layer & $4.1452 \times 10^{3}$ & $4.3248 \times 10^{3}$ & $4.5743 \times 10^{3}$ & $4.9707 \times 10^{3}$ \\
\hline 650 layer & $4.2589 \times 10^{3}$ & $4.3650 \times 10^{3}$ & $4.5944 \times 10^{3}$ & $6.2999 \times 10^{3}$ \\
\hline
\end{tabular}

Table 4.3 Cracks lengths at each layer of bottom sandstone at different stress conditions

\begin{tabular}{l|l|l|l|l}
\hline $\begin{array}{l}\text { Bottom } \\
\text { sandstone }\end{array}$ & $\begin{array}{l}\text { Before } \\
\text { loading } \\
(0 \mathrm{MPa})\end{array}$ & $\begin{array}{l}\text { After the first } \\
\text { phase }(6 \mathrm{MPa})\end{array}$ & $\begin{array}{l}\text { After the second } \\
\text { phase }(18 \mathrm{MPa})\end{array}$ & $\begin{array}{l}\text { After failure } \\
(37.5 \mathrm{MPa})\end{array}$ \\
\hline 350 layer & $4.4808 \times 10^{3}$ & $4.5974 \times 10^{3}$ & $5.0556 \times 10^{3}$ & $8.0700 \times 10^{3}$ \\
\hline 450 layer & $5.0623 \times 10^{3}$ & $5.1282 \times 10^{3}$ & $5.9059 \times 10^{3}$ & $8.4840 \times 10^{3}$ \\
\hline 550 layer & $4.8902 \times 10^{3}$ & $5.0337 \times 10^{3}$ & $5.5458 \times 10^{3}$ & $8.9168 \times 10^{3}$ \\
\hline 650 layer & $4.5148 \times 10^{3}$ & $4.5900 \times 10^{3}$ & $5.0070 \times 10^{3}$ & $8.1470 \times 10^{3}$ \\
\hline
\end{tabular}

found that the cracks lengths of bottom and floor sandstone increased indifferent layers as the cyclic load/unload. From the beginning of unloading phase to the end of the first phase under cyclic load/unload, the cracks growth was small and the surfaces of sandstone were not significantly damaged. From the end of the first stage load/unload to the second stage of cyclic load/unload, the cracks growth were more obvious and the cracking rate of sandstone accelerates. From the second stage of cyclic load/unload to the final failure of sample, the cracks length increased rapidly, and the fracture of sandstone intensified.

\subsubsection{Calculating the Area of Cracks}

The bwarea function of MATLAB software was used to calculate the area with pixel value of 1 in binary image. It could be found that the pixel values in the cracks binary image were 1 pixel area. Different pixel models could use the bwarea function to give different values, and the area of interest target could be obtained by weighting the sum. In order to compensate for the deformation of continuous image with discrete pixel, it must be weighted. For example, a horizontal and vertical image consisting of 50 pixels had a smaller area than the 50-pixel diagonal images. 50pixel can represent the area of image under both horizontal and vertical conditions. However, the area of diagonal image was 62.5 because of weighted operation. The total area of the bwarea function was obtained by summing up all the individual pixel area in the image and the area of single pixel was obtained according to its $2 \times 2$ zones. There were six models for calculating individual pixels. 


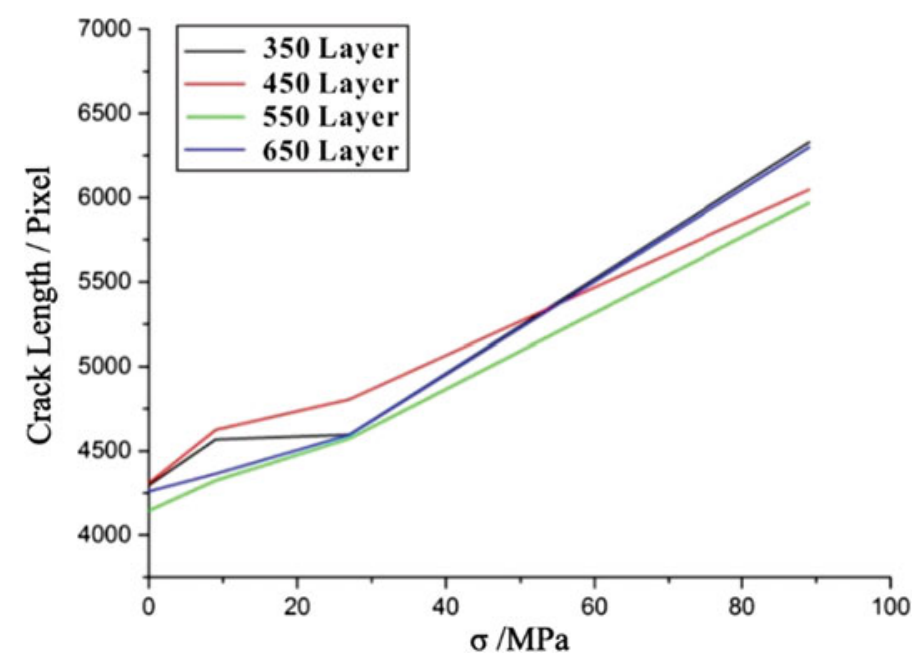

Fig. 4.3 The tendency of cracks length at each layer of roof sandstone at different stress conditions

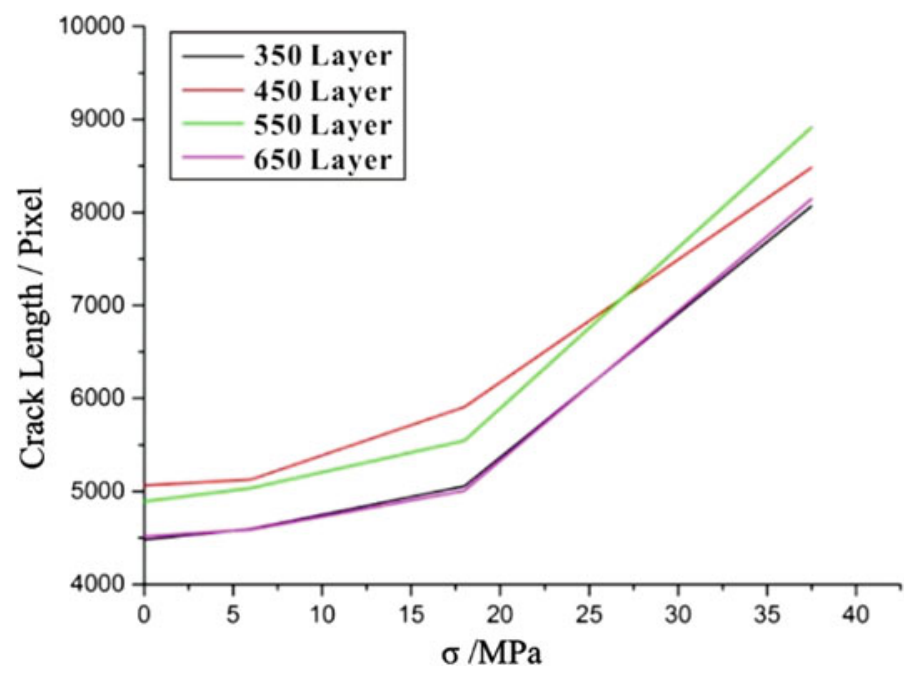

Fig. 4.4 The tendency of cracks lengths at each layer of bottom sandstone at different stress conditions

In the adjacent region, there is no pixel value of " 1 ", and the individual pixel area is 0 ; one pixel has a pixel value of " 1 " and the single pixel area is $1 / 4$; there are two adjacent pixels with the pixel value of "1" and the single pixel area is $1 / 2$; there are two pixels with the value of " 1 ", and the single pixel area is $3 / 4$; there are three pixels with a point of " 1 ", and the area of a single pixel is $7 / 8$; there are four pixels with a point of "1" and the area of a single pixel is 1 . 
Each pixel in a binary image can be viewed as a part of a neighboring region of 4 different $2 \times 2$. Therefore, there is no contiguous, diagonally connected pixel value of " 1 ", and the total area is 1 . The calculation method of BW area of binary image is as follows:

$\begin{array}{llllllll}0 & 0 & 0 & 0 & 0 & 0 & 0 & 0 \\ 0 & 0 & 0 & 0 & 0 & 0 & 0 & 0 \\ 0 & 0 & 1 & 1 & 0 & 0 & 0 & 0 \\ 0 & 0 & 1 & 1 & 0 & 0 & 0 & 0 \\ 0 & 0 & 0 & 0 & 0 & 0 & 0 & 0 \\ 0 & 0 & 0 & 0 & 0 & 1 & 0 & 0 \\ 0 & 0 & 0 & 0 & 0 & 0 & 0 & 0 \\ 0 & 0 & 0 & 0 & 0 & 0 & 0 & 0\end{array}$

The result of calculation is 5 .

The calculation results of cracks area at each layer of roof sandstone at different stress conditions were shown in Tables 4.4, 4.5 and Figs. 4.5, 4.6. We could found that the cracks area of bottom and floor sandstone was increased at different layers as the cyclic load/unload. The evolution was similar as shown in Tables 4.2, 4.3 and Figs. 4.3, 4.4.

Table 4.4 Cracks areas at each layer of roof sandstone at different stress conditions

\begin{tabular}{l|l|l|l|l}
\hline $\begin{array}{l}\text { Roof } \\
\text { sandstone }\end{array}$ & $\begin{array}{l}\text { Before } \\
\text { loading } \\
(0 \mathrm{MPa})\end{array}$ & $\begin{array}{l}\text { After the first } \\
\text { phase }(9 \mathrm{MPa})\end{array}$ & $\begin{array}{l}\text { After the second } \\
\text { phase }(27 \mathrm{MPa})\end{array}$ & $\begin{array}{l}\text { After failure } \\
(89.1 \mathrm{MPa})\end{array}$ \\
\hline 350 layer & $2.6581 \times 10^{5}$ & $2.6653 \times 10^{5}$ & $2.6754 \times 10^{5}$ & $2.7238 \times 10^{5}$ \\
\hline 450 layer & $2.6624 \times 10^{5}$ & $2.6632 \times 10^{5}$ & $2.6721 \times 10^{5}$ & $2.7008 \times 10^{5}$ \\
\hline 550 layer & $2.6533 \times 10^{5}$ & $2.6613 \times 10^{5}$ & $2.6658 \times 10^{5}$ & $2.7019 \times 10^{5}$ \\
\hline 650 layer & $2.6619 \times 10^{5}$ & $2.6693 \times 10^{5}$ & $2.6735 \times 10^{5}$ & $2.7142 \times 10^{5}$ \\
\hline
\end{tabular}

Table 4.5 Cracks areas at each layer of bottom sandstone at different stress conditions

\begin{tabular}{l|l|l|l|l}
\hline $\begin{array}{l}\text { Bottom } \\
\text { sandstone }\end{array}$ & $\begin{array}{l}\text { Before } \\
\text { loading } \\
(0 \mathrm{MPa})\end{array}$ & $\begin{array}{l}\text { After the first } \\
\text { phase }(6 \mathrm{MPa})\end{array}$ & $\begin{array}{l}\text { After the second } \\
\text { phase }(18 \mathrm{MPa})\end{array}$ & $\begin{array}{l}\text { After failure } \\
(37.5 \mathrm{MPa})\end{array}$ \\
\hline 350 layer & $1.3171 \times 10^{5}$ & $1.3185 \times 10^{5}$ & $1.3243 \times 10^{5}$ & $1.3683 \times 10^{5}$ \\
\hline 450 layer & $1.3253 \times 10^{5}$ & $1.3260 \times 10^{5}$ & $1.3383 \times 10^{5}$ & $1.3772 \times 10^{5}$ \\
\hline 550 layer & $1.3223 \times 10^{5}$ & $1.3232 \times 10^{5}$ & $1.3309 \times 10^{5}$ & $1.3626 \times 10^{5}$ \\
\hline 650 layer & $1.3179 \times 10^{5}$ & $1.3185 \times 10^{5}$ & $1.3235 \times 10^{5}$ & $1.3646 \times 10^{5}$ \\
\hline
\end{tabular}




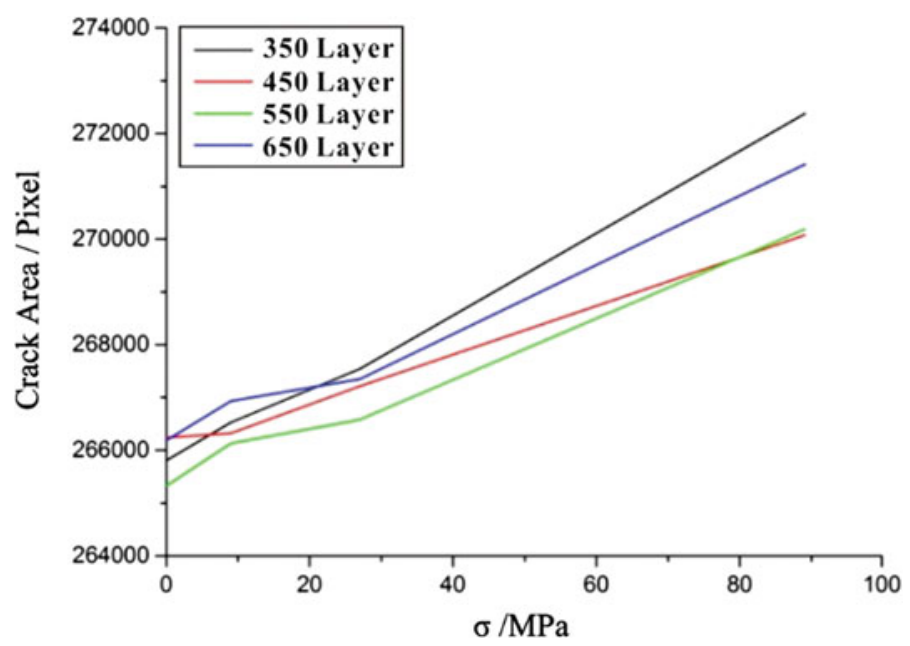

Fig. 4.5 The tendency of cracks area at each layer of roof sandstone at different stress conditions

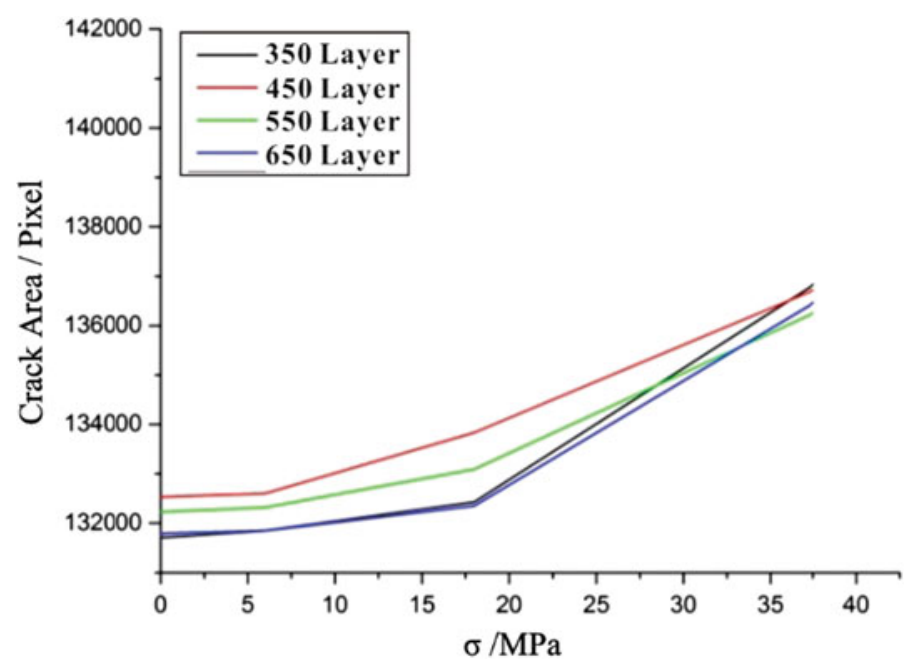

Fig. 4.6 The tendency of cracks area at each layer of bottom sandstone at different stress conditions

\subsection{Three-Dimensional Reconstruction Model and Numerical Simulation}

In order to obtain the influence of mesostructure evolution of rock failure on its macro-mechanical properties, sandstone specimens were scanned by CT. The MIMICS software was used to reconstruct the two-dimensional images of 
fissured rock at the stage of unloading, the microscopic characteristics of sandstone could be reproduced by the reconstructed numerical model. The mechanical response of sandstone specimens was simulated by FLAC software under uniaxial cyclic load/unload.

\subsubsection{Establishing a Three-Dimensional Finite Element Model}

\subsubsection{Establishing the Model of Fissured Rock}

CT scanning was the process of dividing a three-dimensional rock sample into two layers of two-dimensional sections, and then completing the top-down scanning of rock specimens. Using the two-dimensional information obtained from the CT scanning, the $3 \mathrm{D}$ reconstruction of scanned object can be achieved by reverse modeling. If the three-dimensional solid model of real cracks structure in the rock was completed, the cracks structure with uneven distribution in each layer of sandstone was extracted, and then the mesh was divided. The three-dimensional finite element calculation of rock sample could be obtained.

\subsubsection{Three-Dimensional Reconstruction Model of Failured Sandstone}

The concrete process of reconstructing fractured rock under unloaded condition is as follows:

(1) The MATLAB software was used to scan the bin format into TIF format image files, put it into the $3 \mathrm{D}$ reconstruction software, and set the relevant parameters of actual test. The interval scanning was the picture size spacing, and the pixel size was:

$$
\mathrm{a}=\frac{b}{1024}
$$

where the size of scanned image was $1024 \times 1024$ px, and the size of pixel was shown with A. The length of square image was displayed with B. Finally, according to the angle of observation, the direction of model was set.

(2) The software generated the corresponding threshold according to the gray distribution in the image, and the segmentation of region was completed according to the threshold. 
(3) The 3D model of rock sample was generated according to $3 \mathrm{D}$ reconstruction function in software, and the 3D model was not a body model for calculation.

(4) By the system with 3-matic, smoothing the model, the required 3D model could be obtained.

The sandstone images, which were extracted and processed, were analyzed by the $3 \mathrm{D}$ reconstruction software. In order to obtain the visual cracks distribution, three-dimensional model of rock samples needed to be set through a series of parameters. Different materials in the reconstruction of specimen could be distinguished by choosing different thresholds in the CT image, which was convenient for the division of cracks and the rock matrix. The distribution of cracks structure could be reflected in the three-dimensional model of fractured sandstone. The three-dimensional models of rock fracture were shown in Figs. 4.7 and 4.8.

Fig. 4.7 Three-dimensional reconstruction model of fractured rockmass

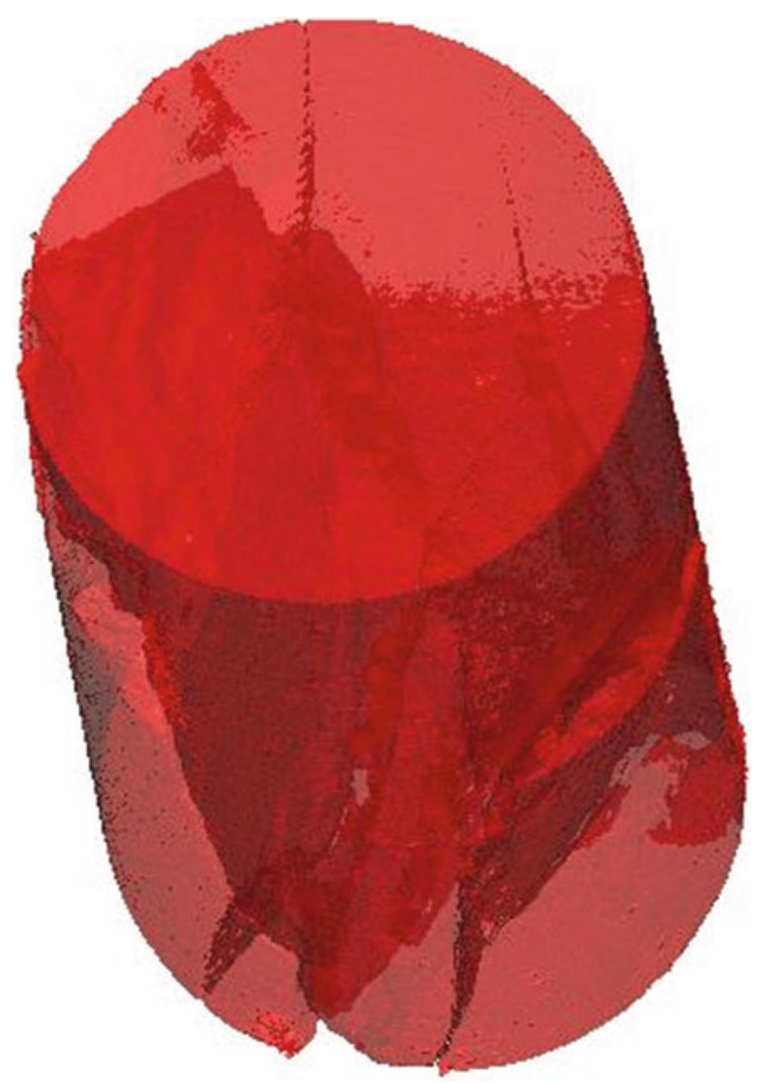


Fig. 4.8 Sectional view of $\mathrm{X}-\mathrm{Y}$ cross section of fractured rockmass

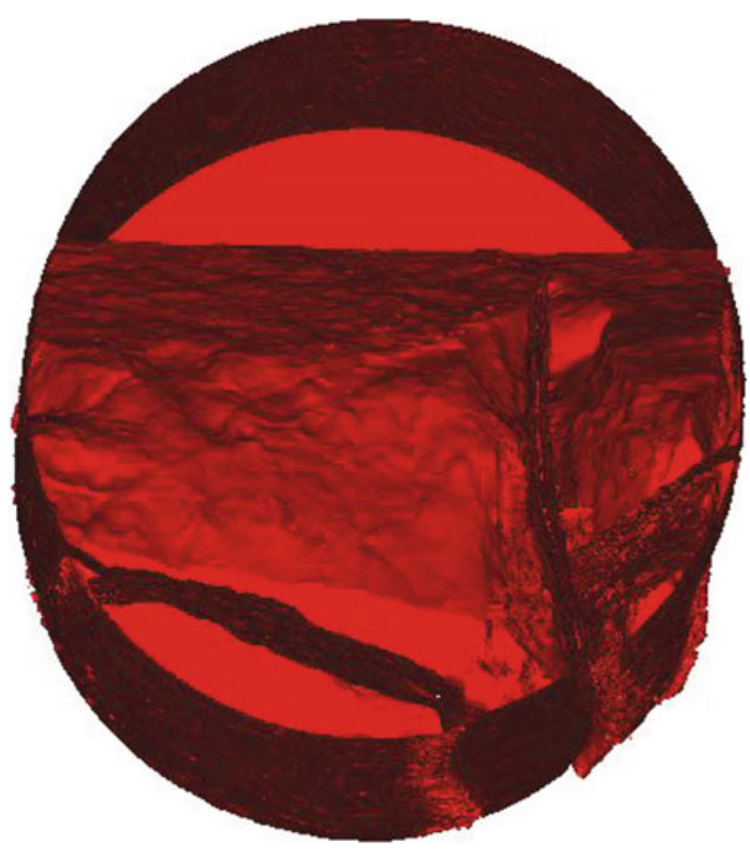

\subsubsection{Mesh Generation of Reconstructed Model}

3-MATIC is supporting of MIMICS software, and has a computer aided design (CAD) pretreatment tool and a pre-processing function of finite element model, it can help the triangular mesh optimization finite element analysis and fluid mechanics analysis, the model of local fairing and quality optimization becomes possible. The generated mesh was shown in Fig. 4.9.

The division of body mesh of model must be optimized. On the basis of generated surface mesh, the model body was divided by the way of continuous rock. The body mesh was generated continuously in the cracks and matrix, and finally the three-dimensional finite element model was established. In this chapter, the reconstruction model was divided into grids; there were 500 thousand information units in the model. The subdivision of 3D volume mesh was shown in Fig. 4.10.

\subsubsection{Three-Dimensional Model Parameters}

MIMICS could assign different material properties to the finite element model, which was generated by $3 \mathrm{D}$ reconstruction according to the different gray values, and the cracks could be distinguished using ANSYS software. Only cracks and matrices were distributed in the model. Therefore, parameters could be settled.

Using the different colors and the gray value of kinds of material, the density and elastic modulus, Poisson's ratio of material was defined as the parameters of model 
Fig. 4.9 Model diagram of mesh after optimization

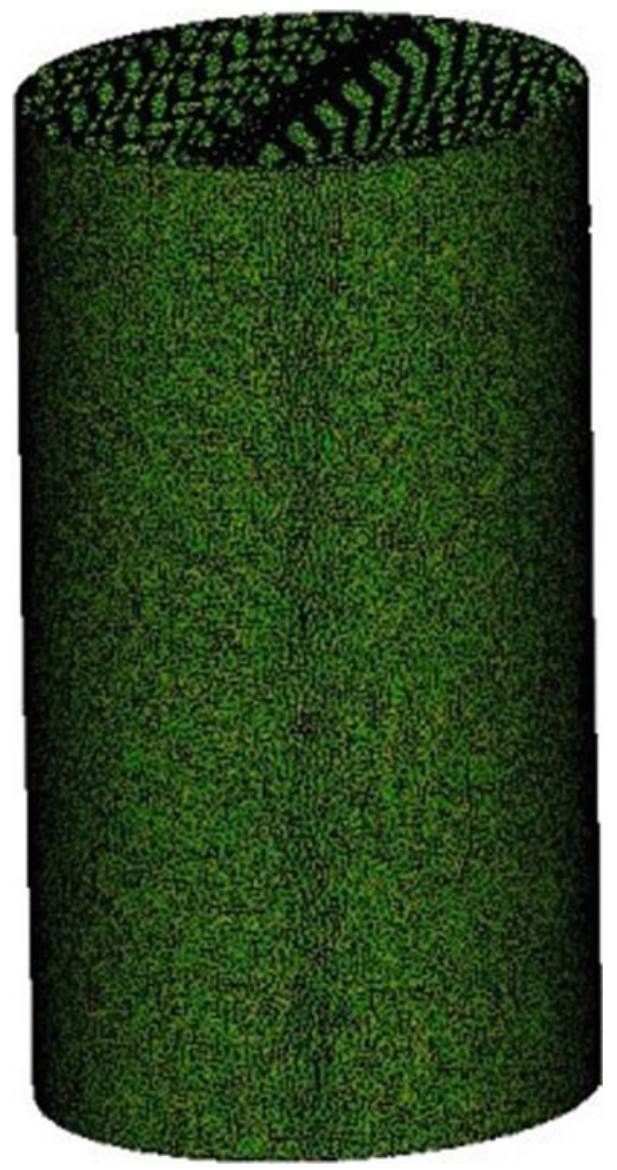

in ANSYS software. Therefore, this step required to definite of material were attributed to distinguish different substances. The process of defining the physi-mechanical parameters of each node unit in the three-dimensional model was shown in Fig. 4.11; the resulting fractured rock model was shown in Fig. 4.12.

\subsubsection{Numerical Simulation of Fissured Rock}

This model was derived for the ANSYS format. In this section, this model could be analyzed and calculated using the grid transformation tool to import into FLAC3D software. Numerical simulation results of three-dimensional fissured rock model could be obtained under uniaxial cyclic load/unload, and the influence of heterogeneity on microstructure of sandstone specimens macrocharacters could be analyzed. The simulation results and actual test results were compared and analyzed in the three dimensional reconstruction model of rock. 
Fig. 4.10 The internal structure of body grid in three-dimensional finite element model

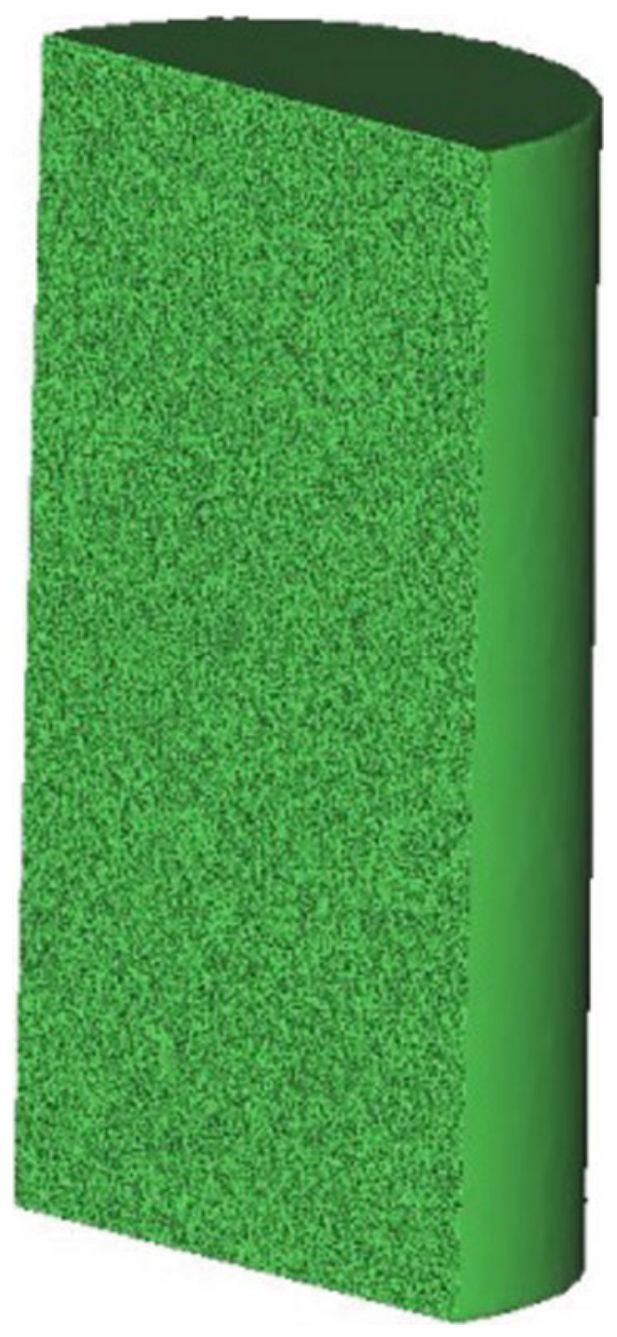

\subsubsection{Selection of Material Parameters}

The model was imported into FLAC3D, in order to avoid the contact problem that internal cracks of sandstone was empty under loading, and reduced the error of numerical simulation results, the fracture was treated as a virtual material, it was not the strength. Therefore, the modulus of elasticity and cohesion of sandstone were less small, the remaining sandstone matrix were uniformly given material parameters (Table 4.6 and Fig. 4.13). 


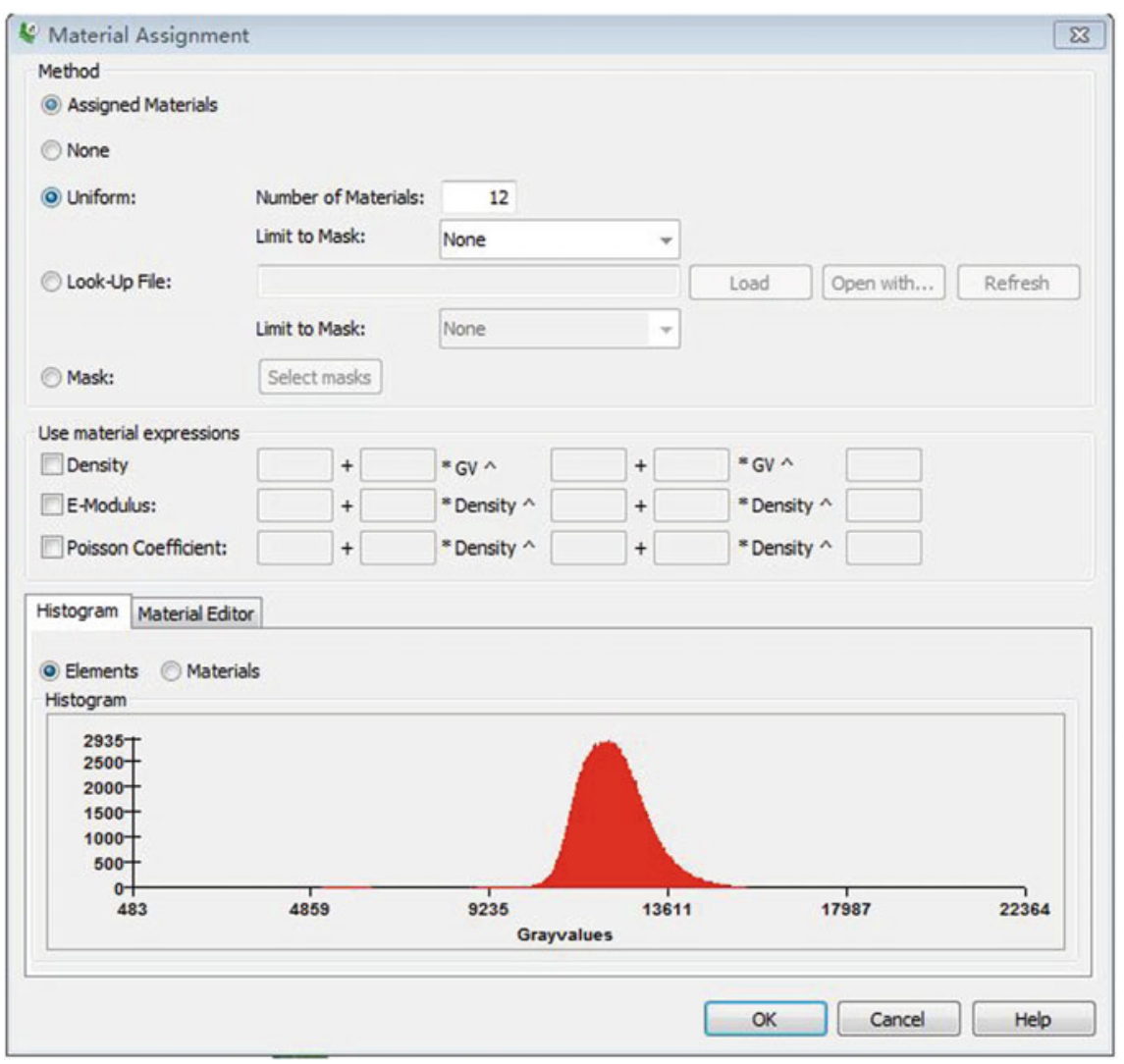

Fig. 4.11 The given different materials of model after the grid partition

\subsubsection{Numerical Analysis of Model}

As shown in Figs. 4.14 and 4.15, in the first stage of cyclic load/unload, numerical simulation results were coinciding with the experimental results, the simulation results of stress-strain curve and actual stress-strain curve was relatively consistent; Results of numerical simulation under load/unload were difference with the actual test results in the second phase under cycle load/unload, this maybe due to the actual test for rock material composition in various, and there were many micro holes and the number of cracks result in the different and the irreversible plastic with the actual test in two level cyclic load/unload process; There were differences between the final failure and the actual situation of damage stage, the specimen surface was not smooth. Due to the 3D reconstruction of rock under uneven surface, the process of displacement loading and the actual process were not consistent.

As shown in Figs. 4.16 and 4.17, the stress concentration of sandstone 3D model appeared in the cracks, and the stress concentration in the fracture deflection was more 

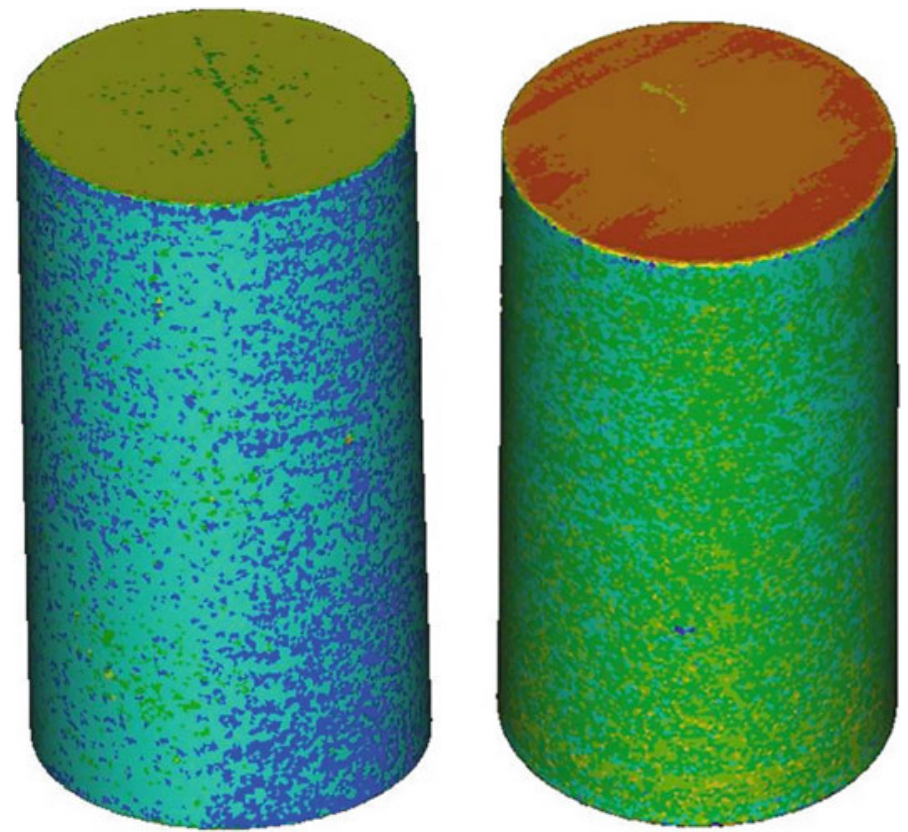

Fig. 4.12 Fissure body models of roof and floor sandstone

Table 4.6 The selection of material parameters of fissured rockmass model in roof and floor sandstone

\begin{tabular}{l|l|l|l}
\hline Media type & Poisson's ratio & Cohesion $(\mathrm{MPa})$ & Internal friction angles $\left(^{\circ}\right)$ \\
\hline Matrix of roof sandstone & 0.26 & 15.81 & 32 \\
\hline Matrix of floor sandstone & 0.25 & 11.92 & 60 \\
\hline Fissure & 0.2 & 0.16 & 40 \\
\hline
\end{tabular}
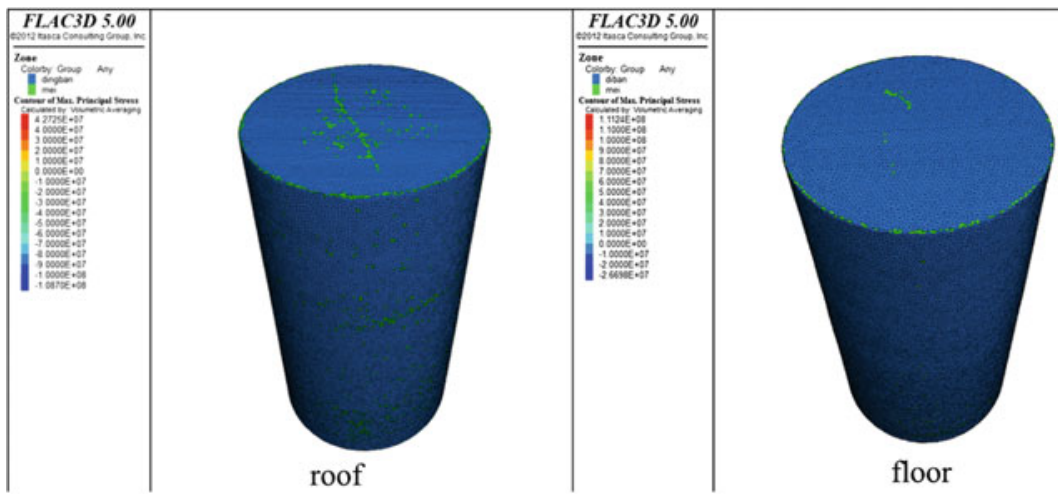

Fig. 4.13 Numerical models of roof and floor sandstone 


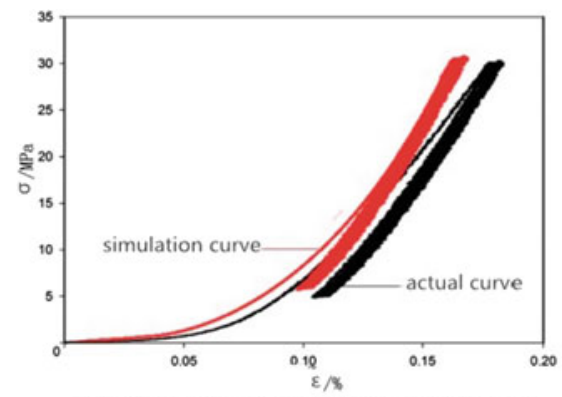

(a) The first stage under cyclic loading and unloading

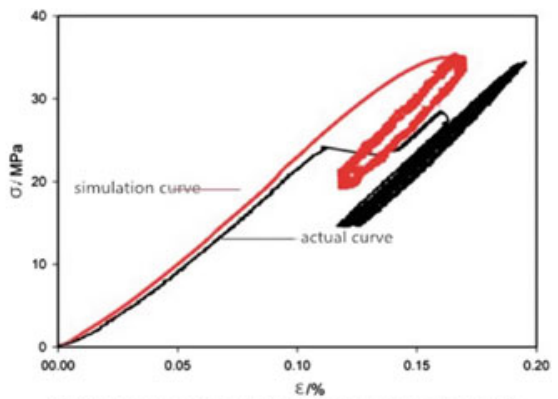

(b) The second stage under cyclic loading and unloading

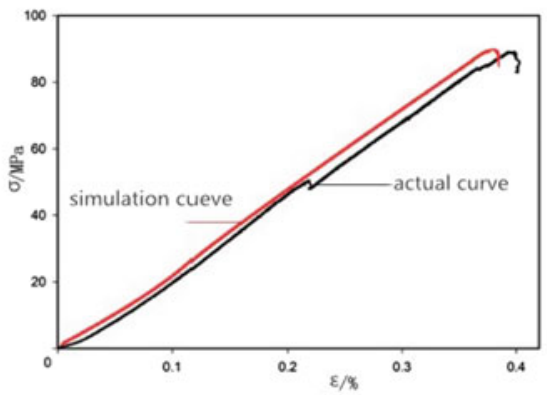

(c) The failure stage under uniaxial loading

Fig. 4.14 Stress-strain comparison charts of roof

obvious. The stress concentration area of these cracks had the tendency to extend to the interior of sandstone matrix; In the early stage of loading, the concentrated stress degree was low because of small load, and the stress concentration was only at the end of cracks, and no obvious failure unit appears; With the increase of stress, many microcracks were generated. With the increase of stress, microcracks would rapidly expand until the whole specimen failure.

The above analysis showed that the macro mechanical properties of sandstone were affected by their internal cracks and spatial distribution. With the increase of stress, the sandstone produced uncoordinated deformation at the cracks, which could result in stress concentration in matrix near cracks, especially at the cracks tip. The stress concentration area were presented the trend to the development of rock samples, the discontinuous small cracks were met and merged, large macro main cracks were formed, and the sandstone samples were failure due to the cracks propagation and coalescence.

In this chapter, numerical simulation results of sandstone samples were selected to analyze the mechanical mechanism of rock failure. As shown in Fig. 4.18, numerical simulations of plastic elements were comprised in the process of change. With the increasing stress, the status model unit of rock failure was also change, the plastic unit reached shear-n shear-p under the action of stress, and the plastic zone was completely through in the failure stage. Taking the red section of compaction 


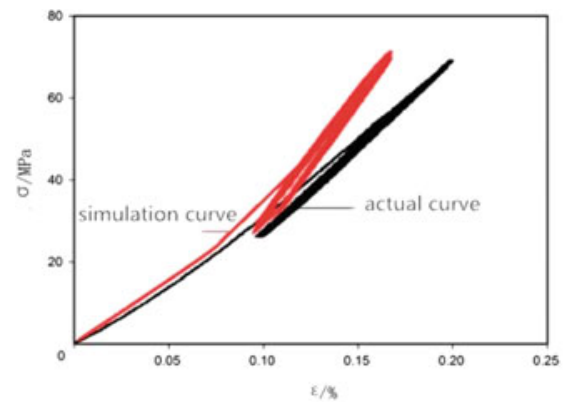

(a) The first stageunder cyclic loading and unloading

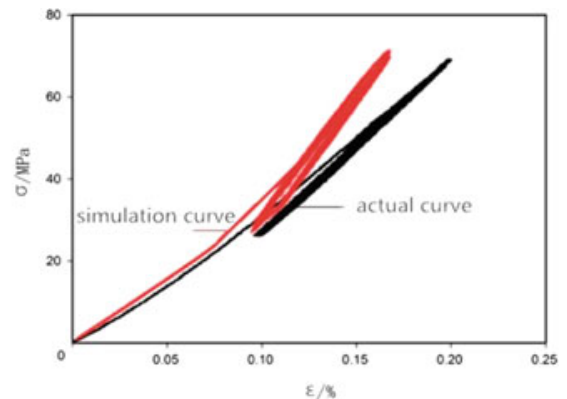

(b) The second stage under cyclic loading and unloading

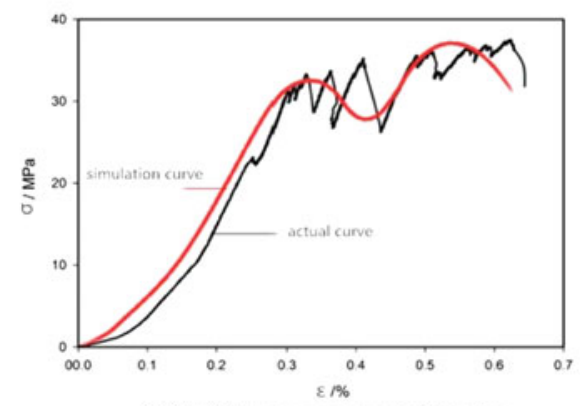

(c) The failure stage under uniaxial loading

Fig. 4.15 Stress-strain comparison charts of floor sandstone specimen

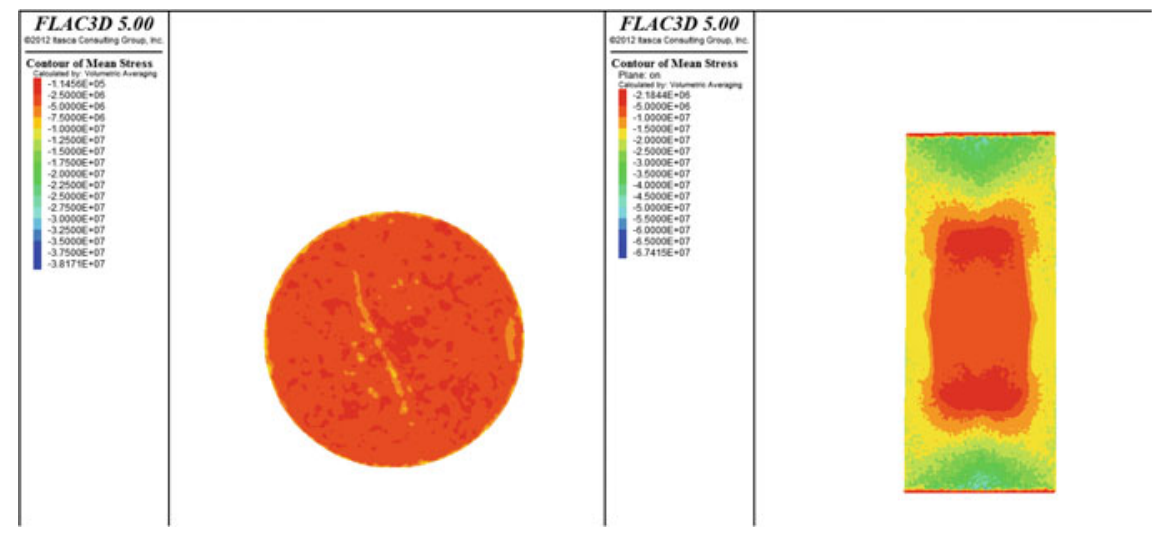

Fig. 4.16 Stress profile of fissures model the roof sandstone

stage as an example, it showed that shear failure was occurring in the shear-n shear-p red plastic unit status at the compaction stage; With the increase of stress, the plastic unit in the first stage of load/unload in the region was shear-p in blue; As the stress continues to increase, the plastic unit in the second stage of load/unload 


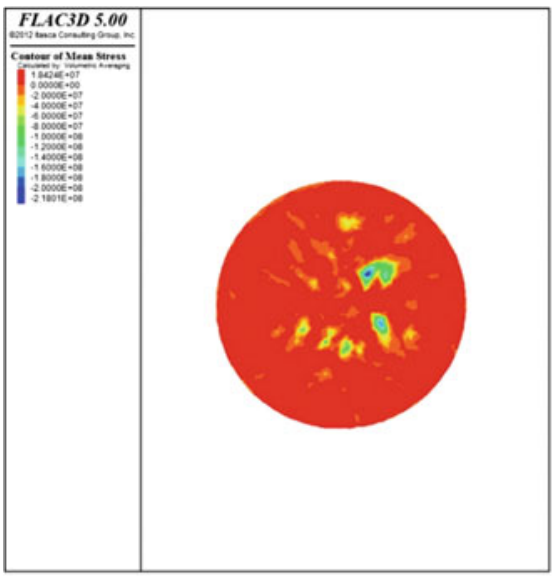

(a) stress distribution of cross - section

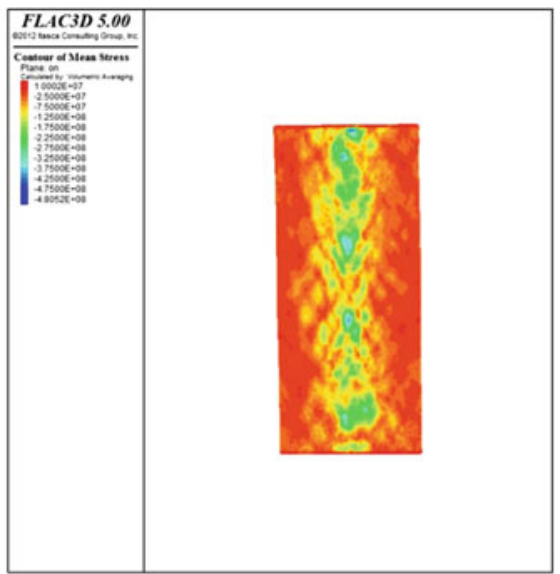

(b) stress distribution of Longitudinal profile

Fig. 4.17 Stress profile of fissures model of bottom sandstone

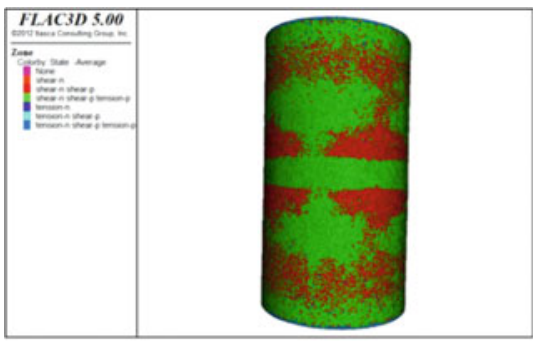

(a) Compression stage

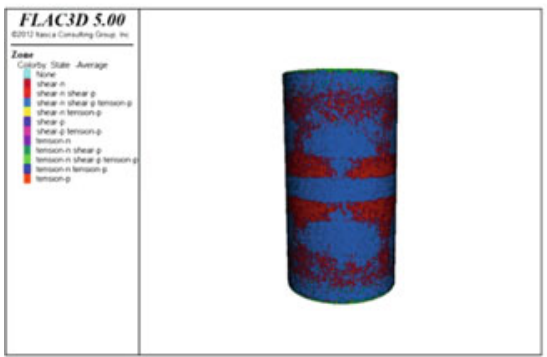

(c) The second stage under cyclic load/unload

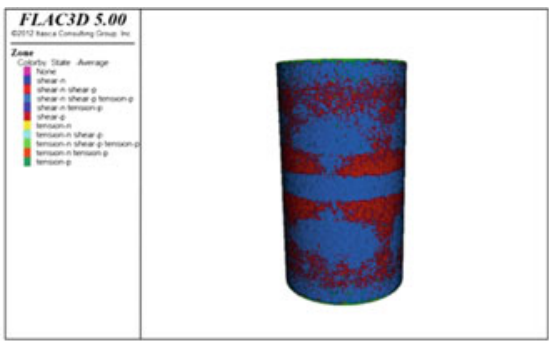

(b) The first stageunder cyclic load/unload

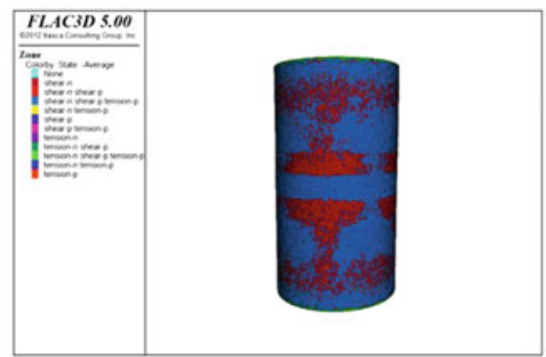

(d) The failure stage under cyclic load/unload

Fig. 4.18 Distribution of plastic units during loading

became tension-n shear-p, and at this stage tensile failure occurs due to Poisson effect; Prior to this, the plastic units only appeared in the local region and did not have a larger range of connectivity. In the failure stage, this region was tension-p 


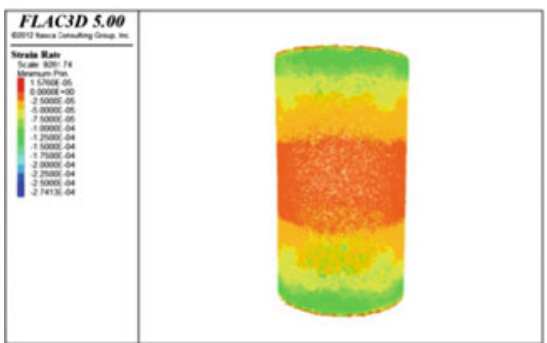

(a) Compression stage

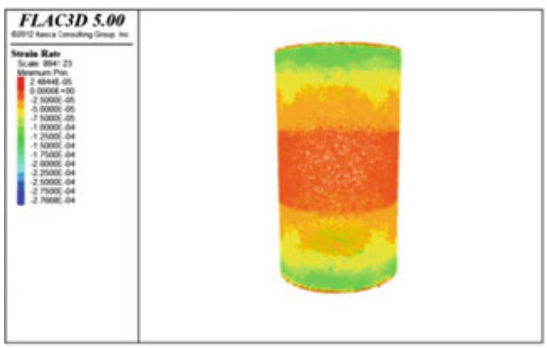

(c) The second stage under cyclic load/unload

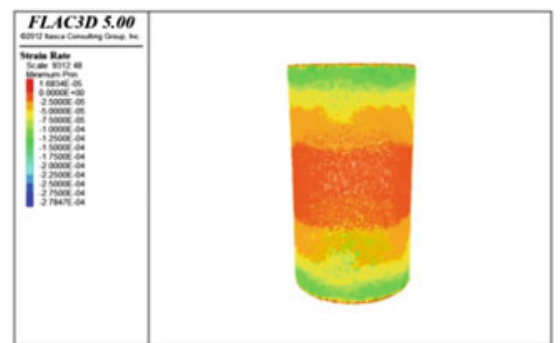

(b) The first stageunder cyclic load unload

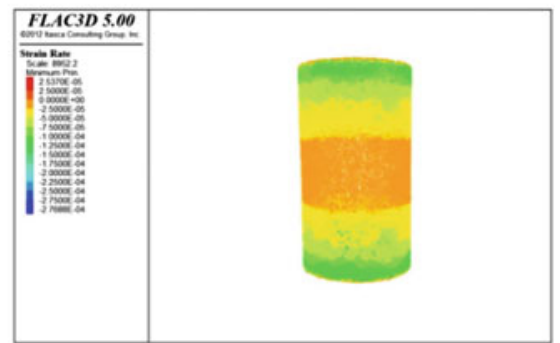

(d) The failure stage under cyclic load/unload

Fig. 4.19 Strain rate of surface during loading

status and tensile failure occurs. This result was consistent with the actual macro failure characteristics.

As shown in Fig. 4.19, it was the strain rate change model in the process of loading. With the increase of stress concentration, the former three stages had different degrees of high strain rate; the strain rate of high concentration would be connected to the local stress concentration zone. With the increasing of stress, the strain rate performance characteristics were from low to high. After the second stage of cyclic load/unload, the local high strain rate concentration zones were met with each other and eventually form a plastic zone at the failure stage.

\section{References}

Argandoña VGRD, Rey AR, Celorio C et al (1999) Characterization by computed X-ray tomography of the evolution of the pore structure of a dolomite rock during freeze-thaw cyclic tests. Phys Chem Earth Part A 24(7):633-637

Bornert M (2010) X-ray micro CT for studying strain localization in clay rocks under triaxial compression. Adv X-ray Tomogr Geomater 118:35

Chen S, Yue ZQ, Tham LG (2007) Digital image based approach for three-dimensional mechanical analysis of heterogeneous rocks. Rock Mech Rock Eng 40(2):145

Feng XT, Chen S, Zhou H (2004) Real-time computerized tomography (CT) experiments on sandstone damage evolution during triaxial compression with chemical corrosion. Int J Rock Mech Min Sci 41(2):181-192 
Kawakata H, Cho A, Kiyama T et al (1999) Three-dimensional observations of faulting process in Westerly granite under uniaxial and triaxial conditions by X-ray CT scan. Tectonophysics 313 (3):293-305

Kawakata H, Cho A, Yanagidani T et al (2000) Gross structure of a fault during its formation process in Westerly granite. Tectonophysics 323(1):61-76

Louis L, Wong T, Baud P et al (2006) Imaging strain localization by X-ray computed tomography: discrete compaction bands in Diemelstadt sandstone. J Struct Geol 28(5):762-775

Nasseri MHB, Rezanezhad F, Young RP (2011) Analysis of fracture damage zone in anisotropic granitic rock using 3D X-ray CT scanning techniques. Int J Fract 168(1):1-13

Ueta K, Tani K, Kato T (2000) Computerized X-ray tomography analysis of three-dimensional fault geometries in basement-induced wrench faulting. Eng Geol 56(1):197-210

Viggiani G, Lenoir N, Bésuelle P et al (2004) X-ray micro tomography for studying localized deformation in fine-grained geomaterials under triaxial compression. C R Méc 332(10):819-826

Wang LB, Frost JD, Voyiadjis GZ et al (2003) Quantification of damage parameters using X-ray tomography images. Mech Mater 35(8):777-790

Open Access This chapter is licensed under the terms of the Creative Commons Attribution-NonCommercial 4.0 International License (http://creativecommons.org/licenses/by-nc/ $4.0 /$ ), which permits any noncommercial use, sharing, adaptation, distribution and reproduction in any medium or format, as long as you give appropriate credit to the original author(s) and the source, provide a link to the Creative Commons license and indicate if changes were made.

The images or other third party material in this book are included in the book's Creative Commons license, unless indicated otherwise in a credit line to the material. If material is not included in the book's Creative Commons license and your intended use is not permitted by statutory regulation or exceeds the permitted use, you will need to obtain permission directly from the copyright holder.

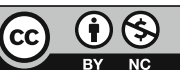

